\title{
Local and distortional biaxial bending capacity of cold-formed steel storage rack uprights
}

\author{
Nima Talebian ${ }^{1}$, Benoit P. Gilbert ${ }^{2}$, Cao Hung Pham ${ }^{3}$, Romain Chariere ${ }^{4}$
}

\begin{abstract}
Rack-supported buildings, also referred to as "clad racks", are currently gaining popularity in the logistic industry. The storage rack, usually manufactured from cold-formed steel members, supports both the building enclosure and the stored goods. Due to the combined action of the wind loading and stored pallets, uprights undergo biaxial bending. Internationally, the design of the uprights is performed in accordance to the provisions in the North American Specification (AISI S100:2012), Australian and NewZeeland standard AS/NZS 4600 (2005) or Eurocode 3 (EN 1993-1-3, 2006) for design of cold-formed steel structures. In these Specifications, a linear interaction equation is used to account for members subject to biaxial bending and may be inaccurate. In order to produce safe and economical design guidelines, the actual interactive relationship between bending about the major and minor axes, for local and distortional buckling, is experimentally investigated in this study for two types of storage rack uprights. Results on perforated and non-perforated uprights are presented and discussed in this paper. Results show that a nonlinear interactive relationship governs the biaxial bending of the studied uprights. This relationship is discussed in some details and compared to the linear equation proposed by the international Specifications. Future studies are also discussed.
\end{abstract}

\section{Introduction}

Cold-formed steel storage racks are common structural systems. They vary from light shelving racks for domestic, archive or shopping applications to large and heavily load bearing industrial systems, up to 30 metres high. They typically consist of upright frames connected by pallet beams. While the vertical uprights are usually mono-symmetric and open sections, the horizontal pallet beams are doublysymmetric and closed sections (Baldassino et al. 2000; Freitas et al. 2005). To ensure fast erection through simple connections between the uprights and the pallet beams, tab connectors are typically welded to the ends of the pallet beams and inserted into perforated uprights. This results in the upright structural behaviour being further complicated by presence of the perforations (Moen and Schafer, 2008; Moen and Schafer, 2010; Casafont et al. 2012). Fig. 1 (a) shows a typical selective storage rack.

\footnotetext{
${ }^{1} \mathrm{PhD}$ candidate, Griffith School of Engineering, Griffith University, Australia, <nima.talebian@griffithuni.edu.au>

${ }^{2}$ Senior Lecturer, Griffith School of Engineering, Griffith University, Australia, <b.gilbert@griffith.edu.au>

${ }^{3}$ Lecturer, School of Civil Engineering, The University of Sydney, <caohung.pham@sydney.edu.au>

${ }^{4}$ Exchange undergraduate student, Griffith School of Engineering, Griffith University, Australia
} 
While steel storage racks are usually free-standing structures built inside an independent building with seldom connections between the two structures, rack-supported buildings, also known as "clad racks", are currently gaining popularity in the logistic industry. In this type of buildings, shown in Fig. 1 (b), the storage racks support both the stored goods and the building enclosure, resulting in more economical buildings. However, due to combined actions of the stored goods, causing the uprights to bend about their axis of symmetry, and wind loads, acting in the plane of the upright frames and causing the uprights to bend about the axis perpendicular to their axis of symmetry, the uprights undergo biaxial bending. The main current cold-formed steel structures design Specifications, including the North American Specification (AISI S100:2012), the Australian and New-Zealand Standard AS/NZS 4600 (2005) and the Eurocode 3 (EN 1993-1-3, 2006), consider a linear interaction equation to design members undergoing bi-axial bending in the form of:

$$
\frac{M_{x}}{M_{b x}}+\frac{M_{y}}{M_{b y}} \leq 1.0
$$

where $M_{x}$ and $M_{y}$ are the applied moments about the two principal cross-sectional $x$ - and $y$-axes, respectively, and $M_{b x}$ and $M_{b y}$ are the moment capacities about the $x$ - and $y$-axes, respectively. However, it is likely that Eq. 1 may not be a linear relationship (Put et al. 1999; Torabian et al. 2015). In order to produce safe and economical design guidelines, the actual relationship for bending the uprights about their two principal cross-sectional axes requires further investigation. Moreover, the presence of regular perforations along the upright length may influence this relationship and also need to be studied.

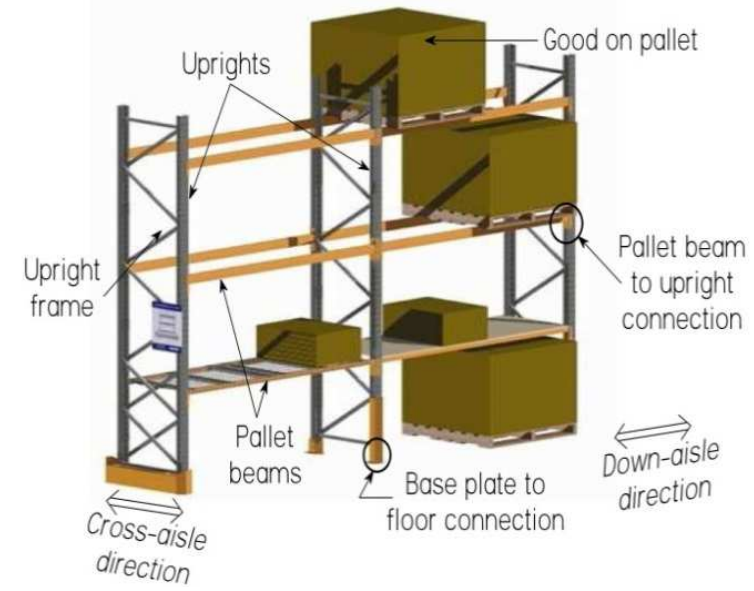

(a)

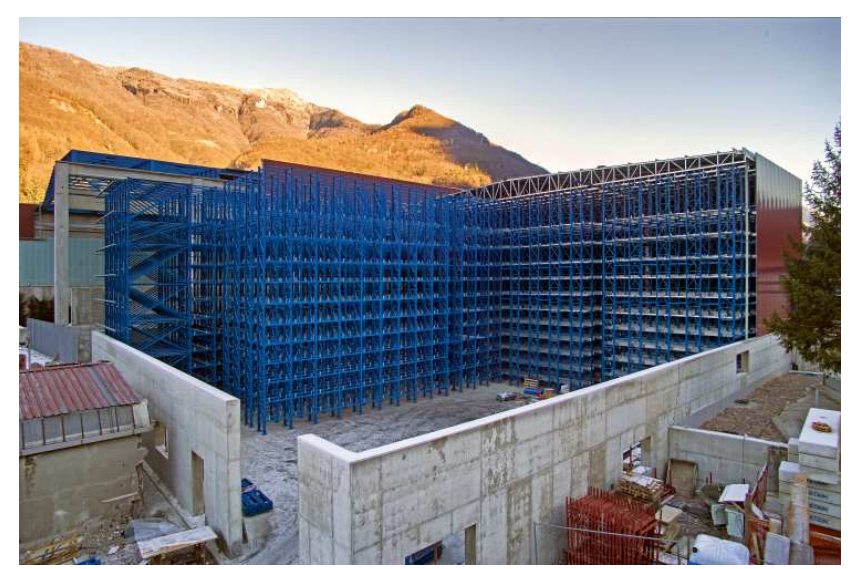

(b)

Figure 1: (a) Typical selective storage rack structure (Gilbert et al. 2012) and (a) clad rack in construction

The capacity of cold-formed steel beams, bent about one of their principal axes, has been widely studied by numerous investigators, such as Nguyen et al. (2006), Wang and Zhang (2009) or Shifferaw and Schafer (2012). However, very limited studies have investigated the biaxial bending behaviour of coldformed steel sections. Put et al. (1999) experimentally investigated the biaxial bending of cold-formed steel Z-sections. Interaction design equations were proposed through an extended series of analytical models. Torabian et al. (2014a, 2014b, 2015) experimentally investigated the behaviour of cold-formed steel lipped C-sections under axial compression and biaxial bending (beam-column). Test results showed 
that a non-linear relationship governs the section capacity. They further developed a new beam-column design method through a comprehensive parametric study using FE models calibrated against experimental results. Compared to current design methods, the new approach was found to predict, on average, a $20 \%$ increase in strength. However, the newly proposed method is conservative.

This paper presents and discusses the experimental results of seventy-eight biaxial bending tests performed on two types of storage rack uprights. In order to investigate both local and distortional buckling failure modes, two different upright lengths per upright type were considered. Uprights with and without regular perforations were also investigated. The test results are also compared to the linear interaction equation currently considered in international design Specifications.

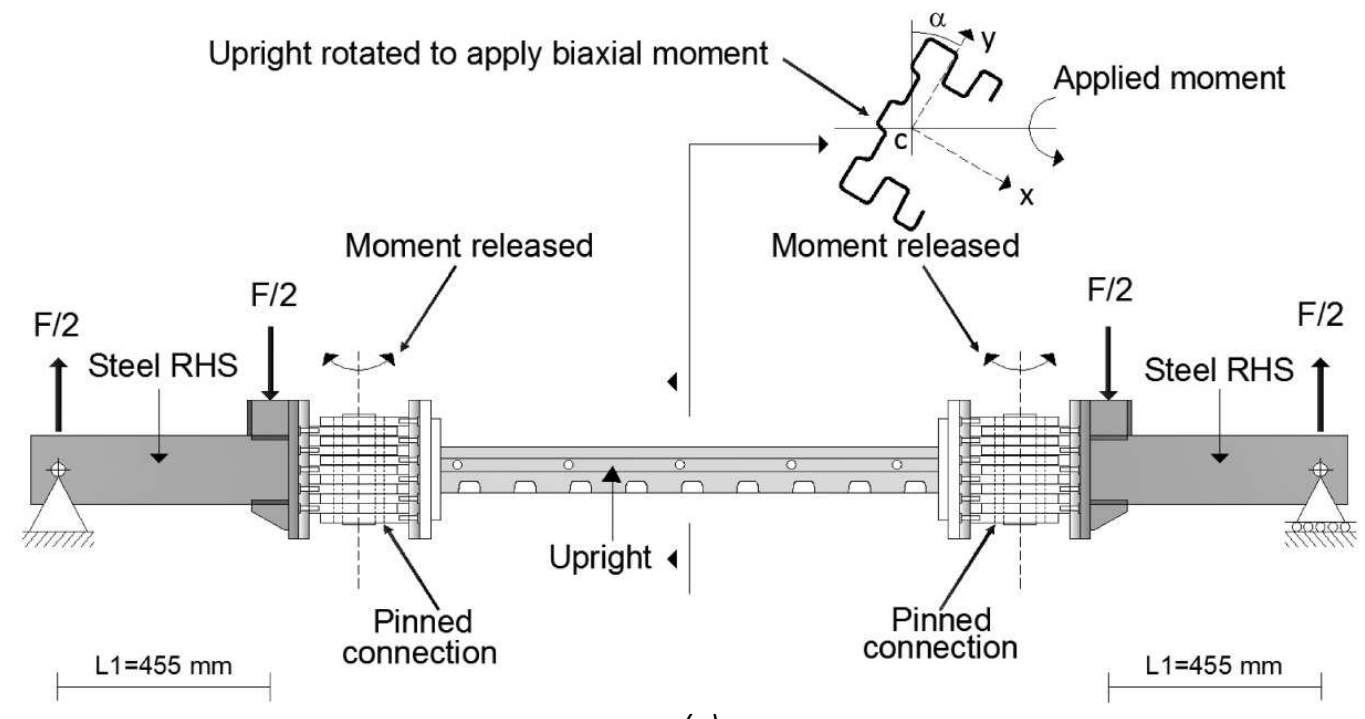

(a)

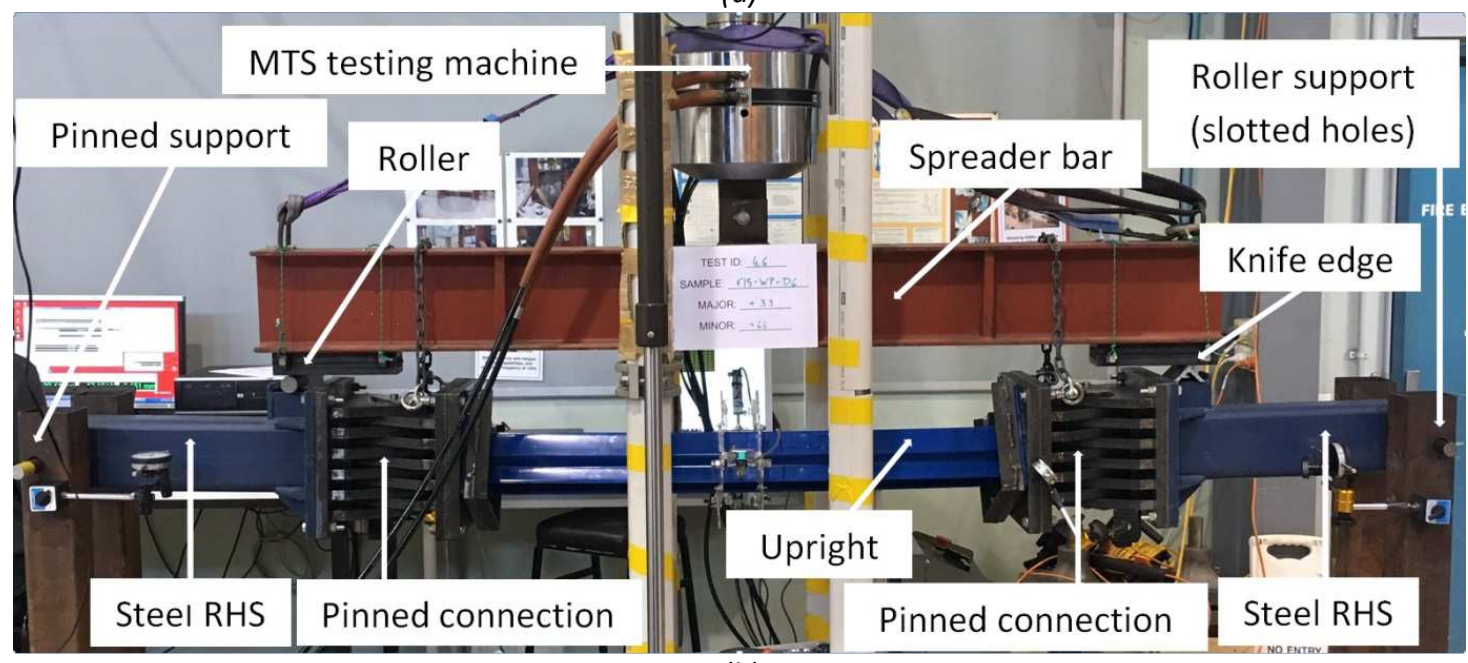

(b)

Figure 2: Experimental test setup (a) schematic and (b) photo

\section{Experimental Test Setup and Measurements}

A four-point bending test configuration was used to test the uprights under pure biaxial bending. Each end of the upright was welded to a $220 \mathrm{~mm} \times 220 \mathrm{~mm}$ square steel plate of $10 \mathrm{~mm}$ thickness. The length of the upright varies, depending of the tested configuration, as explained in detail later in this Section. 
Each upright end was then bolted to two solid pinned connections which were connected to two short lengths of steel Rectangular Hollow Sections (RHS) to form a beam. Fig. 2 shows the test set-up. The formed beam was simply supported and the load was applied using a $500 \mathrm{kN}$ universal MTS testing machine, through a spreader beam, to the steel RHS as shown in Fig. 2. In order to bend the upright about its two principal cross-sectional axes, the upright length was rotated about its centroidal axis, as shown in Fig. 2. The pinned connections were designed with heavy duty roller bearings in order to resist the applied bending moment, while allowing the ends of the uprights to freely rotate about the axis perpendicular to the applied moment. This testing arrangement creates a statically determinate system. An overview test photograph of a solid pinned connection is shown in Fig. 3. The overall applied moment $M$ to the upright length is calculated as:

$$
M=\frac{F L_{1}}{2}+M_{r i g}
$$

where $F$ is the total applied load, $L_{1}=455 \mathrm{~mm}$ is the distance between the supports and the points of application of the loads, as shown in Fig. 2 (a), and $M_{\text {rig }}=0.864 \mathrm{kN} . \mathrm{m}$ is the measured moment applied by the weight of the steel RHS and solid pinned connections to the upright. The moments $M_{x}$ and $M_{y}$ applied about the $x$-axis of symmetry and $y$-axis perpendicular to the axis of symmetry respectively are calculated as:

$$
M_{x}=M \cos (\alpha) \quad \text { and } \quad M_{y}=M \sin (\alpha)
$$

where $\alpha$ is the rotational angle of the cross-section about its centroidal axis shown in Fig. 2 (a).

To prevent the uprights from uplifting in the tension zone through deformation of the end plates, thick Cee-shaped steel plates were bolted with the uprights to the pinned connections and shown in Fig. 4.

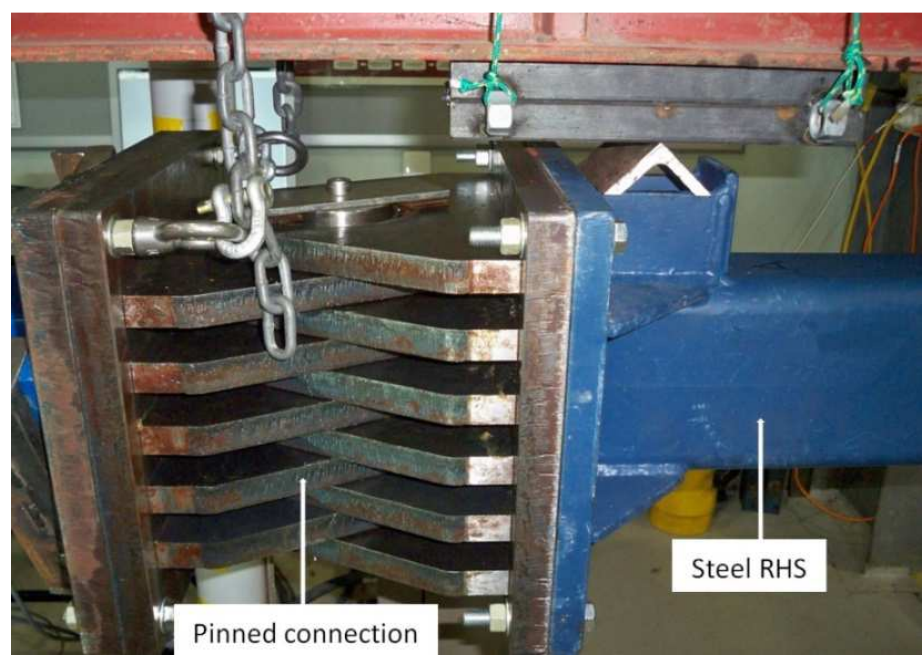

Figure 3: Solid pinned connection

Two different types of storage rack uprights, referred to as "Type A" and "Type B", were tested. While Type $A$ upright has a nominal wall thickness of $1.5 \mathrm{~mm}$ and a width-to-depth ratio of 0.71 , Type $B$ upright has a nominal wall thickness of $2.0 \mathrm{~mm}$ and a width-to-depth ratio of 0.5 . The overall crosssectional shapes and dimensions of the two upright types are shown in Fig. 5 and the main cross- 
sectional properties are given in Table 1. Both upright types are commercially available uprights, at the exception that Type A uprights have been specifically rolled-formed for the purpose of this research to a thickness less than the commercialised uprights. This is to ensure local and distortional failure modes by having the nominal moment capacities for local $\left(M_{b l}\right)$ and distortional $\left(M_{b d}\right)$ buckling, as calculated using the Direct Strength Method (Schafer, 2008) in Clause 7.2.2 of the AS/NZS 4600 (2005), lower than the yield moment $M_{y}$. On the contrary, Type B has a compact section with the nominal moment capacities $M_{b l}$ and $M_{b d}$ equal to the yield moment $M_{y}$.

The length of the tested uprights was calculated running elastic buckling analyses using Finite Element Method (FEM) software package ABAQUS (2015), with fixed end boundary conditions for the upright walls, to ensure that the uprights ideally fail either in local or distortional buckling for bending about the $x$-axis of symmetry. For local buckling, both Types A and B uprights were $400 \mathrm{~mm}$ long, and for distortional buckling, Types A and B uprights were $1100 \mathrm{~mm}$ and $900 \mathrm{~mm}$ long, respectively. To investigate the effect of perforations on the member capacity and biaxial bending interaction, Type $A$ uprights were tested with and without regular perforations along their length. All Type B uprights were perforated.

Table 1: Cross-sectional properties of tested uprights

\begin{tabular}{cccccc}
\hline Upright & $\begin{array}{c}\text { Thickness } \\
(\mathrm{mm})\end{array}$ & $\begin{array}{c}\text { Depth } \\
(\mathrm{mm})\end{array}$ & $\begin{array}{c}\text { Width } \\
(\mathrm{mm})\end{array}$ & $\begin{array}{c}\text { Gross area } / \\
\text { Net area }\end{array}$ & $\begin{array}{c}\text { Second moment of area } \\
I_{x} / I_{y}\end{array}$ \\
\hline Type A & 1.5 & 140 & 100 & 1.108 & 2.52 \\
Type B & 2.0 & 120 & 60 & 1.124 & 5.05 \\
\hline
\end{tabular}

In order to obtain a sufficient number of points to apprehend the biaxial bending interaction curve, seven different bending configurations were tested and shown in Table 2. Tests were repeated twice for each configuration and upright type. However, due to the compactness of the cross-section, type $B$ uprights tested for local buckling tended to fail in the weld between the uprights and the end plates. Several unsuccessful trials were initially made to reinforce the weld, resulting in not enough samples left to test all configurations twice. All configurations were tested once but Configuration 6 in Table 2 which was tested twice. In total, 78 tests were performed in displacement control at a stroke rate of 1.25 $\mathrm{mm} / \mathrm{min}$ for local buckling and $1.5 \mathrm{~mm} / \mathrm{min}$ for distortional buckling, so as to reach failure in 10 to 15 mins.

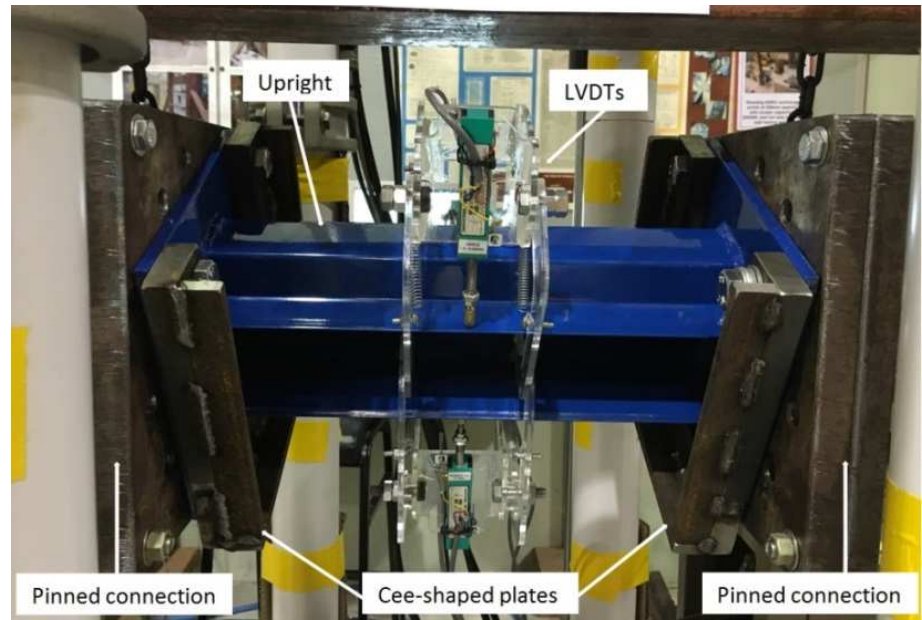

Figure 4: Cee-shaped plates bolted with the uprights to the pinned connections to prevent uplift in the tension zone 


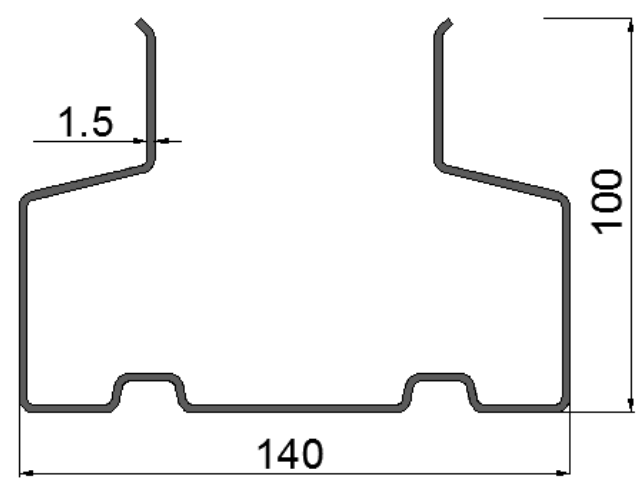

(a)

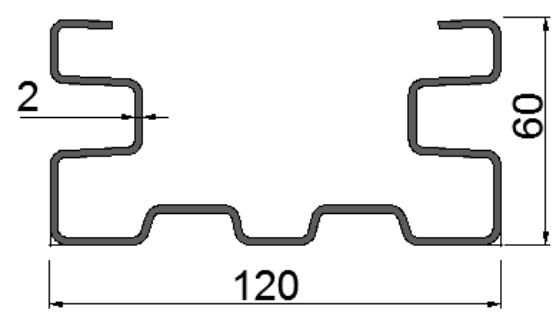

(b)

Figure 5: Overall cross-sectional shape of (a) Type A (b) Type B uprights

Three Linear Variable Displacement Transducers (LVDT) were used to measure the cross-sectional deformation at mid-length of each specimen. For each upright type, a frame was laser cut out of $4.5 \mathrm{~mm}$ thick acrylic sheets and designed to fit around the upright section, a similar method to the one reported in Trouncer and Rasmussen (2014). The LVDTs were attached to the frame and recorded the displacement at the free end of each flange (LVDTs 1 and 3) and at the middle of the web (LVDT 2) as shown in Fig. 6 . As the frame moved with the upright, only the actual cross-sectional deformation due to local and distortional buckling was recorded.

Table 2: Tested biaxial bending configurations

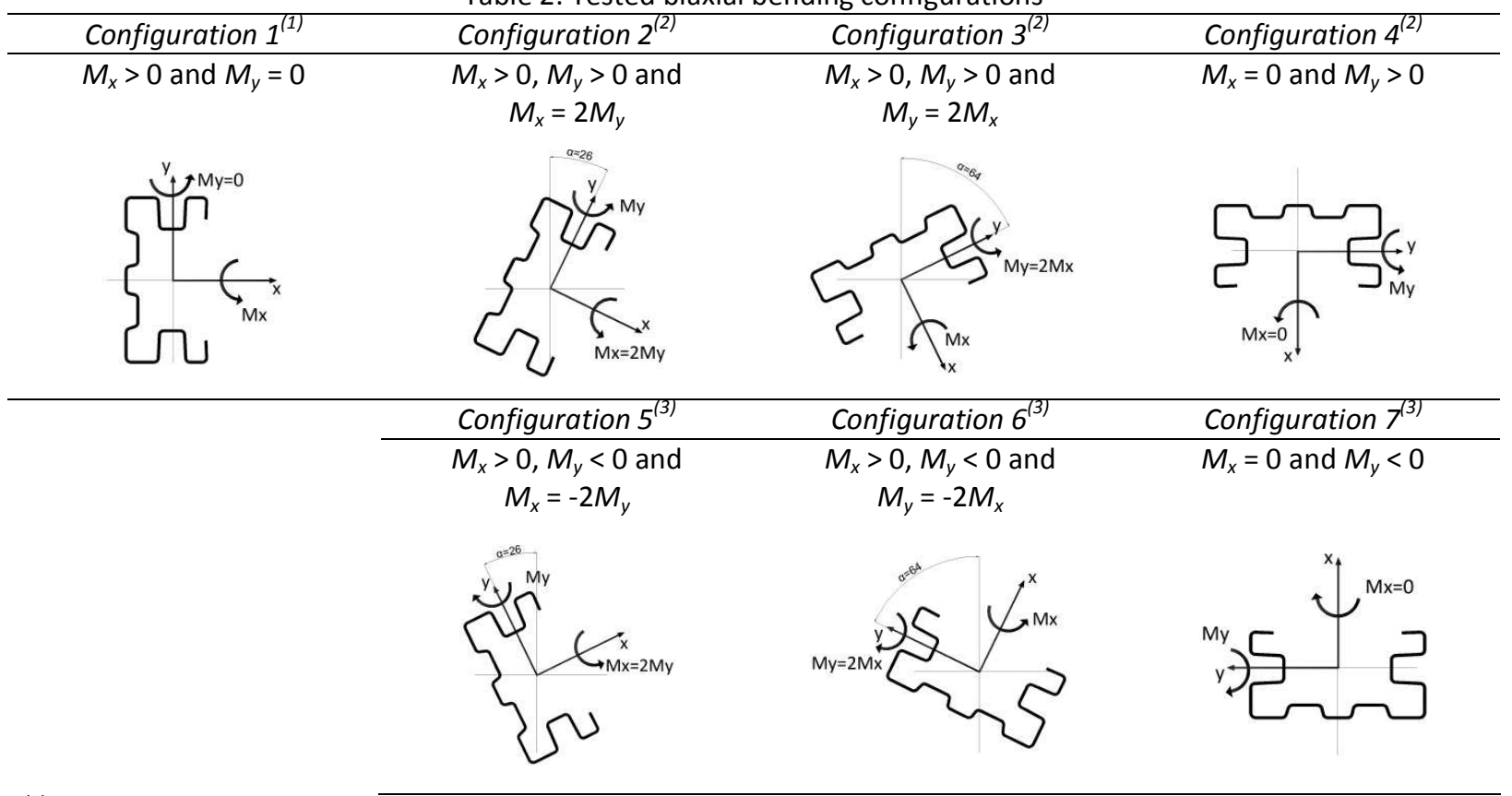

(1): $M_{x}>0$ generates compression in the top flange (as drawn)

(2): $M_{x}>0$ generates compression in the top flange (as drawn) and $M_{y}>0$ generates compression in the web

${ }^{(3)}: M_{x}>0$ generates compression in the top flange (as drawn) and $M_{y}<0$ generates compression in the lip stiffeners 


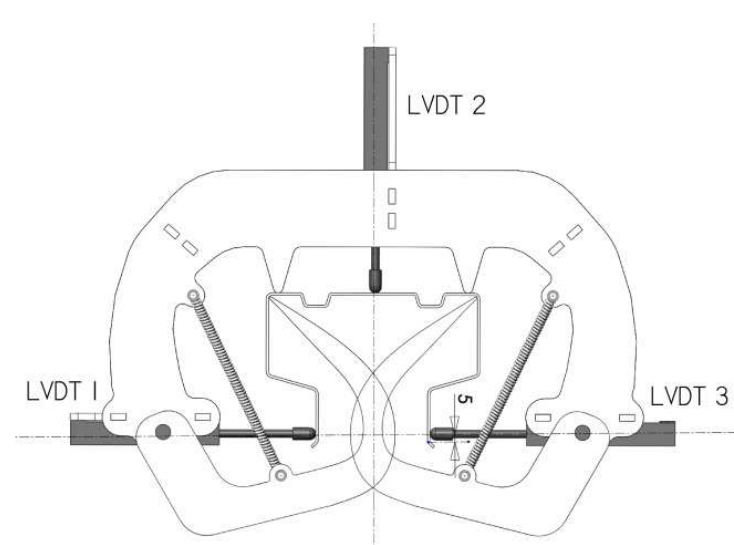

(a)

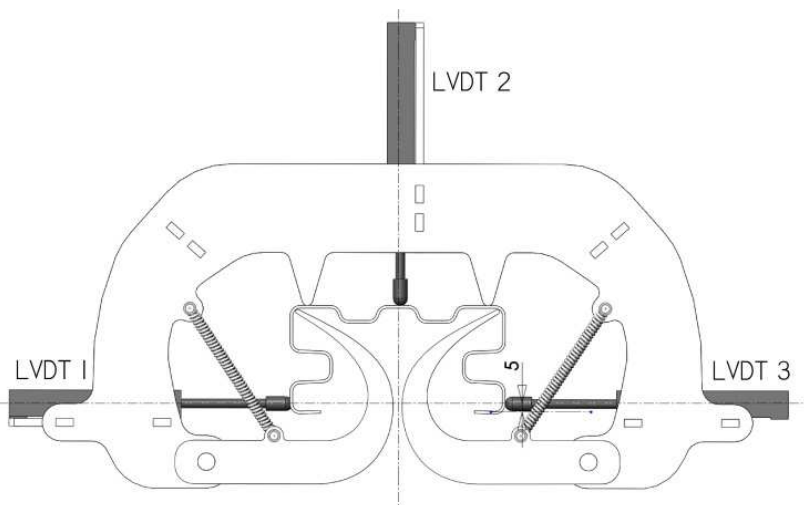

(b)

Figure 6: Transducer frame to measure cross-sectional deformations at mid-height (a) Type A (b) Type B uprights

\section{Test Results}

\subsection{Local buckling}

Fig. 7 plots the deformation of the web (LVDT 2) versus the normalised applied moment $\left(M / M_{\max }\right)$, where $M$ and $M_{\max }$ are the applied and maximum moments, respectively, for all tested short uprights (local buckling) and Configuration 2 (i.e. $M_{x}=2 M_{y}$ ). For Configuration 2, all uprights typically failed in local buckling. Despite being a compact section, Type B upright shows a larger post buckling behaviour, with buckling starting at about $M / M_{\max }=0.7$, than Type $A$ uprights, where buckling occurs at about $M / M_{\max }=0.8$. The observed failure modes for Type $A$ and $B$ uprights, tested in Configuration 2 , are further shown in Fig. 8.

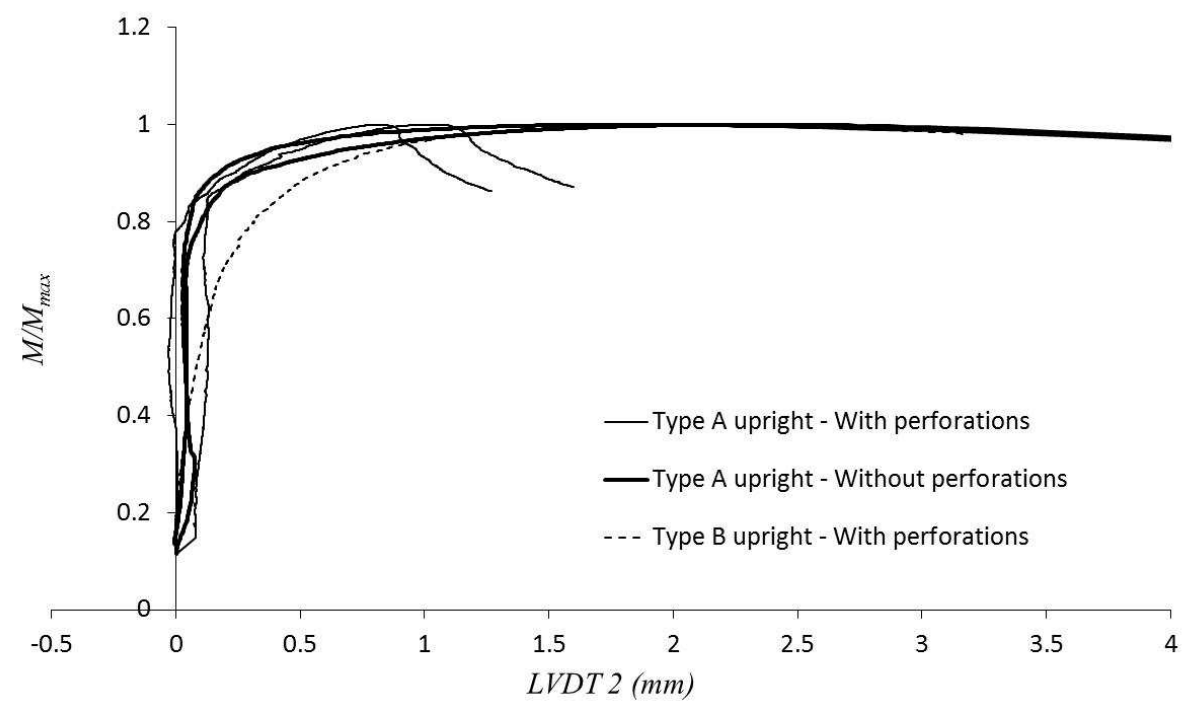

Figure 7: Web deformation (LVDT 2) for all short uprights and Configuration 2

Fig. 9 shows the normalised biaxial bending experimental interaction points obtained from the seven different investigated configurations. In Fig. 9 , the moment capacities $M_{b x}$ and $M_{b y}$ are calculated as the average between two tests when two tests were performed. The linear interaction equation (Eq. 1) in current design Specifications (AISI S100 (2012), AS/NZS 4600 (2005), EN 1993-1-3 (2006)) is also shown in Fig. 9. Fig. 9 shows that the governing interaction relationship is not linear and that Eq. 1 is 
conservative for the tested uprights. No main differences between upright type and perforated and nonperforated uprights are observed. When tested in Configurations 3 and 6, i.e. $M_{y}=+/-2 M_{x}$, the uprights were usually able to sustain a moment $M_{y}$ similar to or greater than the moment capacity $M_{b y}$, when solely bent about the $y$-axis (Configurations 4 and 7). For Configurations 2 and 3 (i.e. $M_{y}>0$ ), at failure Eq. 1 gives an interaction ratio significantly higher than unity, ranging from 1.16 (Type $B$ upright) to 1.47 (perforated Type A upright). For Configurations 5 and $6\left(M_{y}<0\right)$, Eq. 1 gives a ratio less than for $M_{y}>0$ but still higher than unity and ranging from 1.11 to 1.27 , both ratios for non-perforated Type $A$ upright.

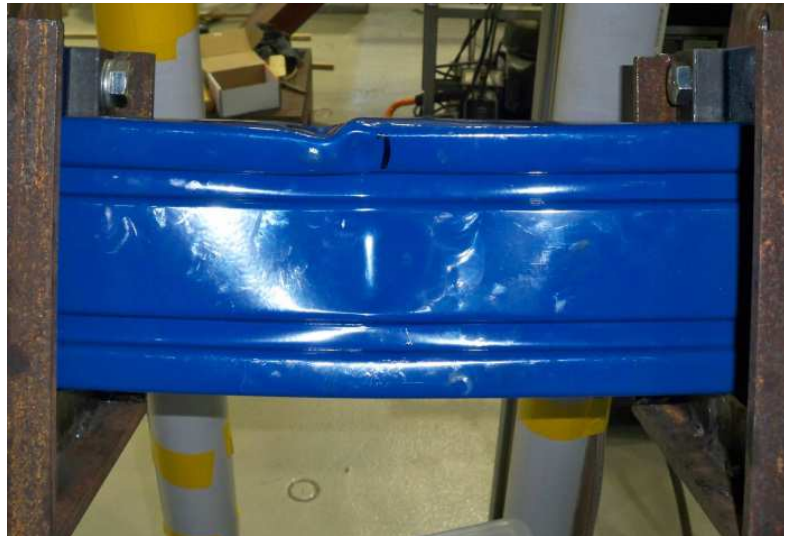

(a)

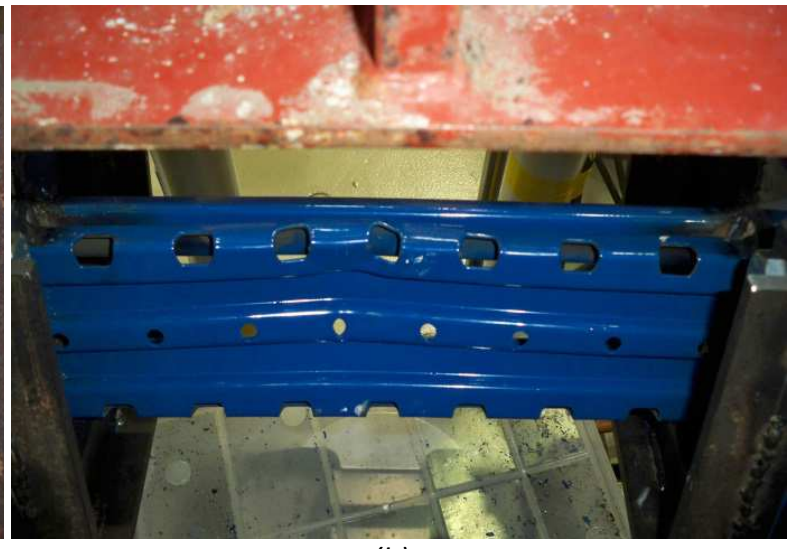

(b)

Figure 8: Local buckling failure mode tested in configuration 2 of (a) Type A and (b) Type B upright

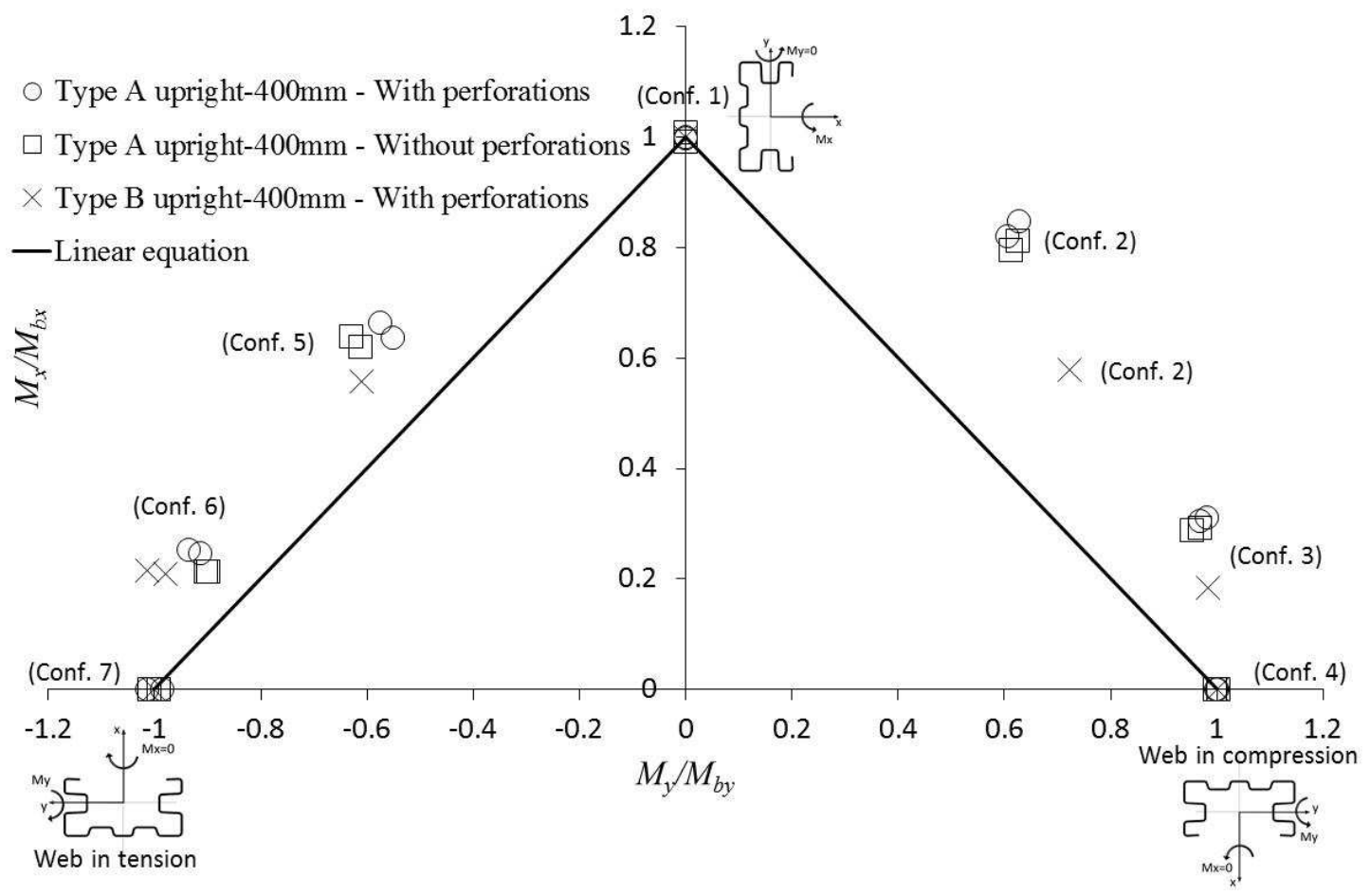

Figure 9: Biaxial bending interaction points for local buckling - All uprights 


\subsection{Distortional buckling}

Fig. 10 plots the cross-sectional opening as the sum of LVDTs 1 and 3 versus the normalised failure moment $\left(M / M_{\max }\right)$ for all tested long uprights (distortional buckling) and Configuration 6 (i.e. $M_{y}=-2 M_{x}$ ). Contrary to Type B uprights that show little to no post-buckling behaviour, Fig. 10 indicates that Type A uprights display a large post-buckling behaviour, with buckling starting at about $M / M_{\max }=0.5$. This behaviour is somewhat different to the short tested lengths of upright failing in local buckling where post-buckling was observed for Type B uprights. Typically, all Type A uprights failed in local-distortional buckling interaction, while Type $B$ uprights failed in distortional buckling at an applied moment close to the first yield moment $M_{y}$. When tested with the web in compression and the lip stiffeners in tension, all uprights failed in local buckling. Fig. 11 (a) and (b) show the local-distortional buckling failure mode interaction for Type A uprights with no perforations and distortional failure mode for Type B uprights, respectively, tested in Configuration 6.

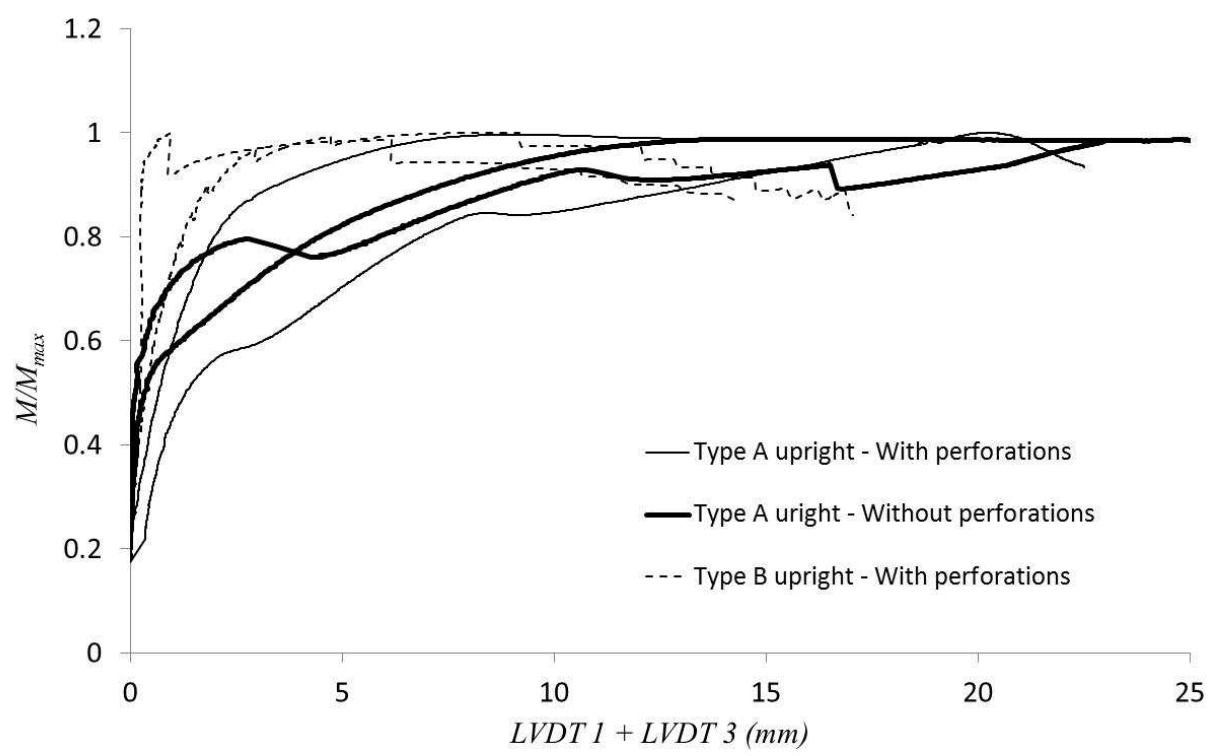

Figure 10: Cross-section deformation (LVDT 1 + LVDT 3) for all long uprights and Configuration 6

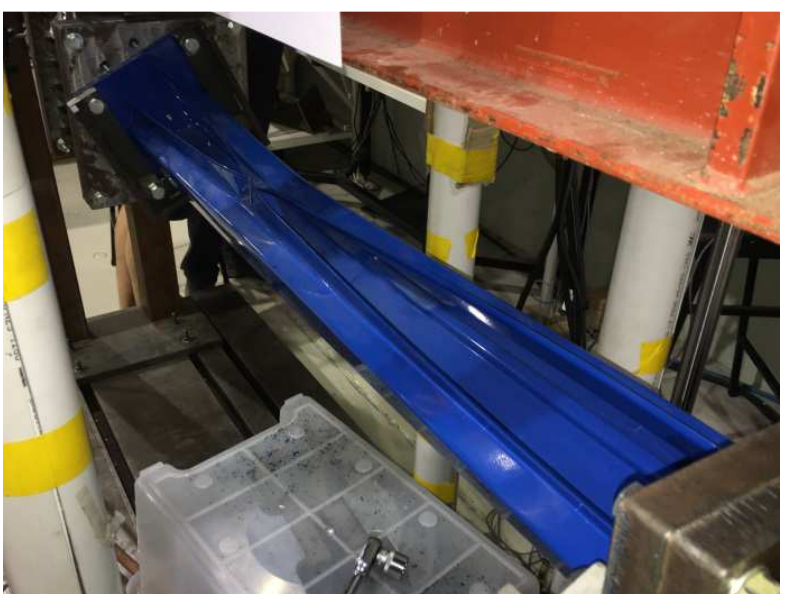

(a)

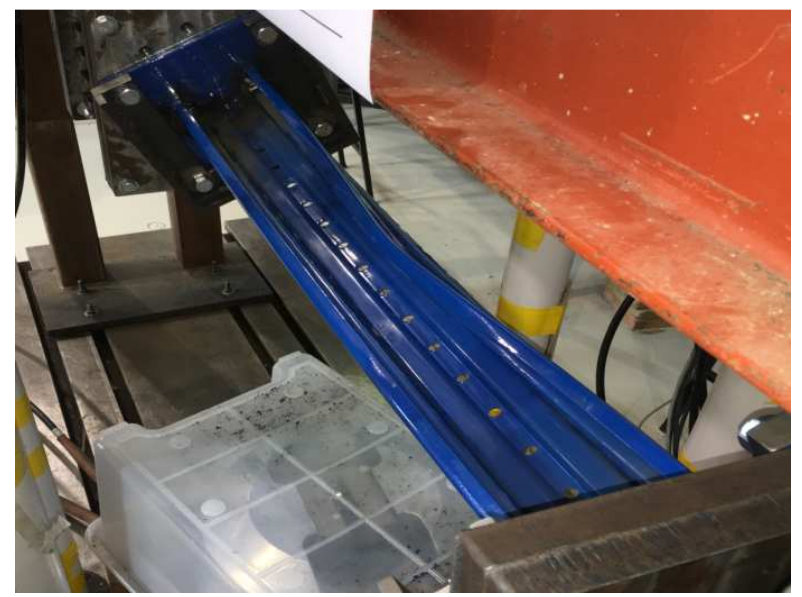

(b)

Figure 11: Configuration 6 (a) Local-distortional buckling failure mode interaction for Type A upright and (b) Distortional failure mode for Type B upright 
Similar to Fig. 9, Fig. 12 shows all normalised biaxial experimental interaction points obtained for distortional buckling. The linear interaction equation in current design Specifications is also shown in the Figure. Similarly to local buckling, Eq. 1 is usually conservative and for all biaxial bending configurations gives an interaction ratio ranging from 1.04 (Type $B$ upright tested in Configuration 5) to 1.68. (perforated Type A upright tested in Configuration 2) at failure. Type B uprights tend to be closer to the linear interaction curve than Type A uprights, especially for Configurations 2 and $5\left(M_{x}=+/-2 M_{y}\right)$.

When tested in Configurations $2\left(M_{x}=2 M_{y}\right)$, type A uprights were able to sustain a moment $M_{x}$ greater than the moment capacity $M_{b x}$, when solely bent about the x-axis (Configuration 1 ). This is explained by different failure modes developing in the cross-section between the two configurations. Configuration 1 failed in local-distortional buckling interaction, and therefore at a lower applied moment than for pure local buckling in Section 3.1, while Configuration 2 failed principally in local buckling at a failure moment similar to the tests performed in Section 3.1. In general, the failure moment for Configurations 2 to 4 is similar to the same in Section 3.1 and the right hand part of the interaction curve in Fig. 12 represents a transition between local-distortional buckling in Configuration 1 to pure local buckling in Configuration 4.

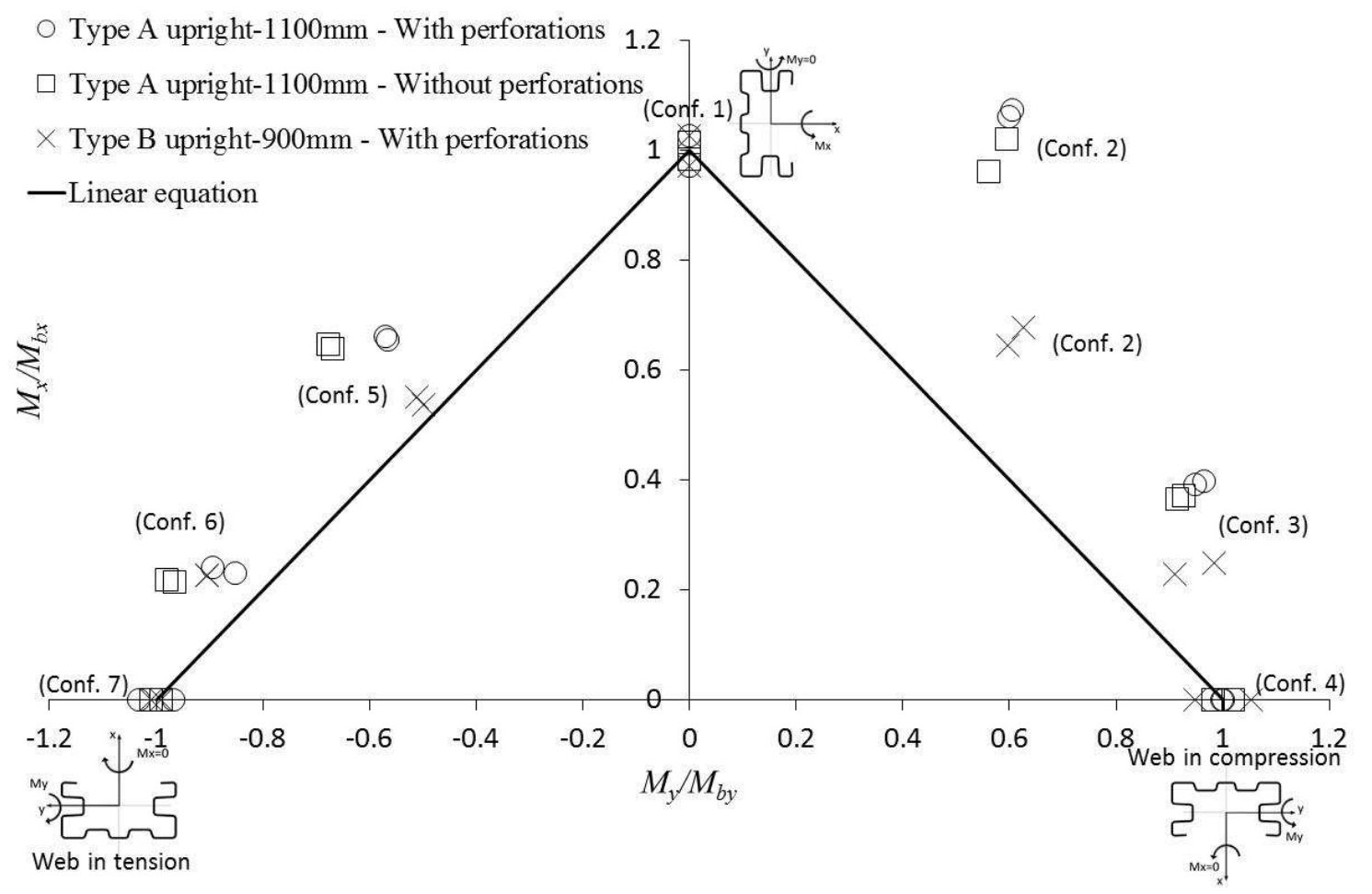

Figure 12: Biaxial bending interaction points for distortional buckling - All uprights

\section{Conclusion}

Experimental results on biaxial bending tests on cold-formed steel storage rack uprights were presented in this study. In total, 78 tests, performed on two upright types with and without regular perforations, were carried out to evaluate the accuracy of the linear biaxial bending design equation in international design Specifications (AISI S100 (2012), AS/NZS 4600 (2005) and EN 1993-1-3 (2006)). Tests were performed for local and distortional failure modes only. The biaxial bending interaction relationship was 
found to be highly nonlinear and the current linear design equation can be significantly conservative. Failure was found to occur at ratio given by the current design equation ranging from 1.04 to 1.68.

\section{Future Studies}

A FE model will be calibrated against the experimental test results presented in this paper. Parametric studies, using a range of existing commercialised storage uprights, will be performed to provide sufficient data to fully apprehend the actual biaxial bending interaction for cold-formed steel storage rack uprights.

Three approaches are planning to be followed and verified to develop design guidelines: (i) the use of an updated interaction equation, (ii) simply calculating the nominal biaxial bending capacity using the current bending DSM design equations and the elastic buckling load obtained by applying the biaxial bending moment to the sections and (iii) calculating the overall member capacity using the proposed beam-column DSM design equations in Torabian et al. (2014a), with the axial load taken equal to zero.

Ultimately, the research will be extended by applying compressive axial loads to the upright to simulate actual loading conditions.

\section{Acknowledgments}

The authors would like to express their gratitude to Mr Tito Cudini from Modulblok S.p.A., Italy, and Modulblok S.p.A. for providing the upright sections free of charge and rolled-forming Type A uprights for the sole purpose of this research. The authors are grateful to the continuous support from Mr Cudini and Modulblok S.p.A..

\section{References}

Abaqus (2015). “Abaqus ver. 6.14 user manual." Providence, U.S.A.: ABAQUS, Inc.

AISI-S100 (2012). "North American Specification for the design of cold-formed steel structural members." Washington (DC, USA): American Iron and Steel Institute.

Baldassino, N., Bernuzzi, C. (2000). "Analysis and behaviour of steel storage pallet racks." Thin-Walled Structures, 37 (4) 277-304.

Casafont, M., Pastora, M., Bonadaa, J., Roure F., Peköz, T. (2012). "Linear buckling analysis of perforated steel storage rack columns with the Finite Strip Method." Thin-Walled Structures, 61 71-85.

EN 1993-1-3 (2006). "Design of steel structures." European Committee for Standardisation.

Freitas, A.M.S., Freitas, M.S.R., Souza, F.T. (2005). "Analysis of steel storage rack columns." Journal of Constructional Steel Research, 61 (8) 1135-1146.

Gilbert, B.P., Rasmussen, K.J.R., Baldassino, N., Cudini, T., Rovere, L. (2012). "Determining the transverse shear stiffness of steel storage rack upright frames." Journal of Constructional Steel Research, 78 107-116.

Nguyen, N.T.B, Fung, T.C., Young, B. (2006). "Strength and behavior of cold-Formed steel Z-Sections subjected to major axis bending." ASCE Journal of Structural Engineering, 132 (10) 1632-1640.

Moen, C.D., Schafer, B.W. (2008). "Experiments on cold-formed steel columns with holes." Thin-walled structures, 46 (10) 1164-1182.

Moen, C.D., Schafer, B.W. (2010). "Direct strength method for design of cold-formed steel columns with holes." ASCE Journal of Structural Engineering, 137 (5) 559-570.

Put, B.M., Pi, Y.L., Trahair, N.S. (1999). "Biaxial Bending of Cold-Formed Z-Beams." ASCE Journal of Structural Engineering, 125 (11) 1284-1290.

Schafer, B.W. (2008). "Review: The Direct Strength Method of cold-formed steel member design." Journal of Constructional Steel Research, 64 (7-8) 766-778.

Shifferaw, Y., Schafer, B.W. "Inelastic Bending Capacity of Cold-Formed Steel Members." ASCE Journal of Structural Engineering, 138 (4) 468-480.

Standards Australia (2005). "AS/NZS 4600: Cold-formed steel structures.” Sydney: Australia: Standards Australia. 
Torabian, S., Zheng, B., Schafer, B.W. (2014a). "Development of a new beam-column design method for cold formed steel lipped channel members." Proceedings of 22nd International Specialty Conference on Cold-Formed Steel Structures, St. Louis, Missouri, USA.

Torabian, S., Zheng, B., Schafer, B.W. (2014b). "Experimental study and modeling of cold-formed steel lipped channel stub beam-columns." Proceedings of the Annual Stability Conference Structural Stability Research Council, Toronto, Canada: SSRC.

Torabian, S., Zheng, B., Schafer, B.W. (2015). "Experimental response of cold-formed steel lipped channel beamcolumns." Thin-walled structures, 89 152-168.

Trouncer, A.N., Rasmussen, K.J.R. (2014). "Flexural-torsional buckling of ultra light-gauge steel storage rack uprights." Thin-walled structures, 81 159-174.

Wang, H., Zhang, Y. (2009). "Experimental and numerical investigation on cold-formed steel C-section flexural members." Journal of Constructional Steel Research, 65 1225-1235. 